\title{
Factors associated with falls in hemodialysis patients: a case-control study
}

\author{
Ignacio Perez-Gurbindo ${ }^{1}$ \\ (D) https://orcid.org/0000-0001-9938-7302 \\ Ana María Álvarez-Méndez \\ (1D) https://orcid.org/0000-0002-9796-7730 \\ Rafael Pérez-García ${ }^{2}$ \\ (D) https://orcid.org/0000-0001-7783-8280 \\ Patricia Arribas-Cobo ${ }^{2}$ \\ (D) https://orcid.org/0000-0002-8069-7762 \\ María Teresa Angulo-Carrere \\ (D) https://orcid.org/0000-0001-5176-6418
}

${ }^{1}$ Universidad Complutense de Madrid, Facultad de Enfermería, Fisioterapia y Podología, Madrid, Madrid, Spain.

${ }^{2}$ Hospital Universitario Infanta Leonor, Servicio de Nefrología, Madrid, Madrid, Spain.
Objective: to identify possible associations between a higher probability of falls among hemodialysis patients and laboratory values, comorbidities, pharmacological treatment, hemodynamic changes, dialysis results and stabilometric alterations. Method: this was a retrospective case-control study with hemodialysis patients. Patients in a hemodialysis unit who had suffered one or more falls were included in the case group. Patients from the same unit who had not suffered falls were the controls. Data were gathered from the patients' clinical history and also from the results of a balance test conducted six months before the study. Results: thirty-one patients were included (10 cases and 21 controls). Intradialytic body weight change was significantly greater among cases ( $p<0.05)$. Patients in the case group also presented greater lateral instability after dialysis ( $p<0.05)$. Other factors such as high blood pressure, antihypertensives, beta-blockers, and lower heart rates were also associated with falls. Conclusion: a greater intradialytic weight change was associated with an increase in risk of falls. Nursing staff can control these factors to prevent the incidence of falls in dialysis patients.

Descriptors: Postural Balance; Accidental Falls; Renal Dialysis; Risk Factors; Body Weight Changes; Clinical Nursing Research.

\section{How to cite this article}

Perez-Gurbindo I, Alvarez-Mendez AM, Perez-Garcia R, Arribas-Cobo P, Angulo-Carrere MT. Factors associated with falls in hemodialysis patients: a case-control study. Rev. Latino-Am. Enfermagem. 2021;29:e3505. [Access $\underset{\text { month }}{\mathrm{f}} \underset{\mathrm{fay}}{\frac{1}{\mathrm{y}}} \mathrm{i}$; ; Available in: DOI: http://dx.doi.org/10.1590/1518-8345.5300.3505 


\section{Introduction}

Moderate to severe Chronic Kidney Disease (CKD) (stages $3-5$ ) affects $6.8 \%-9.5 \%$ of the population(1) and involves the accumulation of waste substances such as uremic toxins, which cannot be eliminated due to impaired renal function. In Latin America the prevalence of patients treated with hemodialysis (HD) is 451 per million inhabitants( ${ }^{(2)}$. In these circumstances, patients must undergo dialysis several times a week, with the aim of eliminating uremic toxins and excess fluids, as well as rebalancing the concentrations of ions and other substances, which affect the body's homeostasis. These biochemical alterations affect the functioning of organs and systems related to balance; in fact, hyponatremia, which affects $6 \%-29 \%$ of patients receiving $\mathrm{HD}^{(3)}$, has been associated with an increased risk of falls.

The excess liquid that must be extracted from patients varies depending on the weight gain that they experience in the interdialytic period and the difference between their calculated optimum weight or dry weight, which is defined as weight when there is no fluid excess or deficiency, without the presence of detectable peripheral edemas, with normal blood pressure, and with no postural hypotension. The excess volume is removed during dialysis, which lasts about 4 hours. The higher the weight gain, the higher the ultrafiltration rate required, resulting in an increased risk of hypotension during dialysis or postHD orthostatic hypotension ${ }^{(4-5)}$, both situations associated with greater morbidity and mortality in patients receiving $\mathrm{HD}^{(6-7)}$.

Therefore, HD produces hemodynamic changes and acute homeostasis, affecting postural control. Previous studies have observed that, after HD sessions, patients suffer changes in postural control(8-9). Likewise, severe $C K D$, even when treated by $H D$, results in the progressive deterioration of structures involved in balance. One example is HD-related amyloidosis ${ }^{(10)}$, which affects joints such as the hip, which plays an important role in postural control in older adults ${ }^{(11)}$. In addition, patients treated with HD usually have other comorbidities, which require treatment and in many cases lead to the polymedication of HD patients, which poses a greater risk of falls ${ }^{(12)}$.

Consequently, numerous factors may place HD patients' postural control at risk. Preventing falls in HD patients is essential, because the consequences in terms of quality of life, associated morbidity and reduction in life expectancy are very important ${ }^{(13-14)}$. The nursing staff in charge of our dialysis unit is responsible for connecting, supervising and disconnecting the dialyzed patient. In these processes, clinical situations can occur, which are already contemplated by protocols, given that greater postural instability is observed after the sessions. In turn, other subclinical situations possibly related to the factors already mentioned continue to pose a risk, which keeps the incidence of falls high among our patients, at levels similar to those observed in prevalence studies, in which the incidence was between 1-1.6 falls per patient-year ${ }^{(15-16)}$.

The aim of this study was to identify possible associations between a higher probability of falls among hemodialysis patients and the laboratory values, comorbidities, pharmacological treatment, hemodynamic changes, dialysis results and stabilometric alterations.

\section{Method}

\section{Study design}

This was a retrospective case-control study with a ratio of 1 case/ 2 controls, with hemodialysis patients. The STROBE (Strengthening the Reporting of Observational Studies in Epidemiology) guide for observational studies was followed, as recommended by the EQUATOR network.

\section{Study location and period}

The study was conducted in the hemodialysis unit of the Infanta Leonor University Hospital (HUIL), in Madrid (Spain), between January and October 2019.

\section{Participants}

The study was conducted with 31 patients: 10 cases and 21 controls matched by age, sex and years receiving dialysis treatment. Patients with prevalent CKD treated with HD three times a week were included and voluntarily agreed to participate in the study. Patients who presented central neurological pathologies, vestibular or visual alterations without optical correction, deformations of the locomotor system and those who could not remain standing were excluded.

Patients in the hemodialysis unit who had suffered one or more falls in the last 6 months and who reported this in the questionnaires administered monthly by the nursing staff were considered cases $(n=10)$. Thus, the participants were unaware that the event "fall" was what categorized them as cases in the study. The controls $(n=21)$ were patients from the same unit who did not report falls during the study period and they were also blind to this criterion. The nurses who had collected the data relative to falls were also unaware of this study.

\section{Data collection}

After the cases were recruited, the researchers reviewed the patients' medical records with their prior consent, using IBM's SPSS ${ }^{\circledR}$ (Statistics Package for the Social Sciences) to create a database with all the information. Laboratory values, medication, hemodynamic values during the dialysis sessions and session values 
obtained by the dialyzer were analyzed. We also evaluated a balance study conducted 6 months earlier in these same patients, using an AMTI AccuGait force platform, previously validated by other study ${ }^{(17)}$. In this study, each patient underwent a stabilometry test before (preHD) and immediately after (postHD) the same dialysis session.

\section{Variables}

The researchers gathered the following information regarding the general characteristics of the patients: age, sex, body mass index (BMI) and years in renal replacement therapy.

Laboratory variables collected from the patients' medical records included sodium ( $\mathrm{mEq} / \mathrm{L}$-milliequivalent per liter), potassium ( $\mathrm{mEq} / \mathrm{L})$, calcium (mg/dL-milligrams per deciliter), phosphorus ( $\mathrm{mg} / \mathrm{dL}$ ) and beta- 2 microglobulin protein. The values of the most recent lab tests were considered. All of them were continuous variables.

The most frequent comorbidities in patients treated with HD were diabetes, high blood pressure (HBP) and heart disease. The number of medications each patient took simultaneously was counted and categorized according to criteria already described in the variable polymedication, which was considered positive if the patient took 4 or more drugs. These were all dichotomous categorical variables.

The HD variables recorded by the dialyzer at the start of the study and included in the analysis were total ultrafiltration (UF), Kt and Kt/v. UF is the fluid removed from the blood through the dialysis membrane. Kt and $\mathrm{Kt} / \mathrm{v}$ are measures based on the urea kinetic model and have been classically used to express the dialysis dose and to estimate the efficacy of the dialyzer. Kt represents urea clearance $(K)$ multiplied by the time of $H D(t)$ and $\mathrm{Kt} / \mathrm{v}$ is $\mathrm{Kt}$ divided by the volume ( $\mathrm{v}$ ) of urea distribution. All these factors were continuous quantitative variables.

Hemodynamic variables collected before and after HD were also analyzed. The following were recorded: 1) systolic blood pressure (SBP), diastolic blood pressure (DBP) and pulse pressure; 2) heart rate; 3) dry weight, preHD weight and postHD weight. Changes and differences between preHD and postHD variables were calculated. All these factors were continuous quantitative variables.

The stabilometry variables studied as factors were extracted from a stabilometry study conducted with hemodialized patients 6 months prior to this study and all the patients that composed this sample were included. In this stabilometry study, the balance of patients was tested before and after HD, following the same protocol for all patients, which had been used previously in a similar study ${ }^{(18)}$. The tests were carried out by two people trained to handle the platform in an office prepared for this purpose, where the lighting conditions were the same throughout the day. The variables analyzed were: 1) average displacement range of the center of pressure (CoP) on the $Y$ axis ( $Y$ range) and $X$ axis ( $X$ range) measured in $\mathrm{cm}$ (centimeter); 2) maximum and average velocity (Vymax, Vxmax and Vavg) of these movements measured in cm/s (centimeter/second); and 3) the area that included the displacement of the CoP with $95 \%$ confidence (Area95) measured $\mathrm{cm}^{2}$ (square centimeters). All these factors were continuous quantitative variables.

\section{Data processing and analysis}

After the database was built, it was cleansed. The Kolmogorov-Smirnov (K-S) test was used to determine whether continuous variables followed a normal distribution. The results of the continuous quantitative variables were expressed as mean \pm standard deviation.

The comparison of means of the different quantitative factors between the cases and the controls was carried out using the Student's t-test or the Mann-Whitney test, according to the distribution presented by the analyzed variables. The comparison of the frequency of the different qualitative factors in the case and control groups was performed using the chi-square test $\left(\mathrm{X}^{2}\right)$ for qualitative variables. $P$ values $<0.05$ were considered significant in Pearson's test. The odds ratio (OR) was calculated, in addition to confidence intervals (CI) at $95 \%$.

The area under the ROC (Receiver Operating Characteristic) curve was calculated to obtain the discriminatory cut-off point of the variable difference in weight between cases and controls. Youden's J statistic was calculated to determine the optimal cut-off point ${ }^{(19)}$. This index is defined by sensitivity + specificity-1. Its value can range from -1 to 1 and equals zero when the test values yield the same proportion of positive results in the control group and the case group, thus rendering the test useless. A value of 1 indicates a perfect test.

Statistical analysis was performed using IBM software ${ }^{\circledR}$ SPSS Statistics 15.0 Inc. Chicago, IL.

\section{Ethical aspects}

This study was approved by the Ethics Committee (HUIL-HGUGM) with the title "Balance disorders in patients with chronic kidney disease on hemodialysis (HD)", under protocol code: HUIL - 18/001; protocol version: 4.5 and version date: February 15, 2019.

\section{Results}

A total of 31 patients, $19(61.3 \%)$ men and 12 (38.7\%) women, participated in the study. No significant gender differences were found among the cases ( 6 men and 4 
women) and the controls (13 men and 8 women). Table 1 shows the differences between cases and controls in terms of age, BMI, years treated with HD, laboratory variables, comorbidities and polymedication status. Participants in the case group were 10 times less likely to be hypertensive than the control group $(\mathrm{OR}=0.105,95 \% \mathrm{CI}=0.02-0.71)$. A significant difference was observed between mean levels of beta- 2 microglobulin between cases and controls, with a $95 \%$ confidence level, the mean levels of cases were 0.09 9.39 higher than controls $(95 \% \mathrm{CI}=0.09-9.39)$.

Table 1 - Differences in analytical variables and frequency of comorbidities between cases (falls) and controls (no falls) in hemodialysis patients $(n=31)$ at the Nephrology Service of the Infanta Leonor University Hospital. Madrid, Spain, 2019

\begin{tabular}{|c|c|c|c|}
\hline & Cases & Controls & \\
\hline Age (years) & $66.3 \pm 11.78$ & $71.43 \pm 11.83$ & $p^{*}=0.268$ \\
\hline BMI $\left(\mathrm{kg} / \mathrm{m}^{2}\right)^{\dagger}$ & $28.66 \pm 5.62$ & $19.36 \pm 43.3$ & $p^{*}=0.857$ \\
\hline $\begin{array}{l}\text { Years in dialysis } \\
\text { treatment }\end{array}$ & $10.5 \pm 9.19$ & $7.53 \pm 8.02$ & $p^{*}=0.374$ \\
\hline \multicolumn{4}{|c|}{ Analytical variables } \\
\hline Sodium $(\mathrm{mEq} / \mathrm{L})^{\ddagger}$ & $138.2 \pm 2.9$ & $139.29 \pm 1.9$ & $p^{*}=0.22$ \\
\hline $\begin{array}{l}\text { Potassium } \\
(\mathrm{mEq} / \mathrm{L})\end{array}$ & $5.42 \pm 0.77$ & $4.95 \pm 0.54$ & $p^{*}=0.06$ \\
\hline Calcium $(\mathrm{mg} / \mathrm{dL})^{\S}$ & $8.46 \pm 0.38$ & $8.58 \pm 0.5$ & $p^{*}=0.51$ \\
\hline $\begin{array}{l}\text { Phosphorus (mg/ } \\
\mathrm{dL} \text { ) }\end{array}$ & $4.87 \pm 1.74$ & $4.43 \pm 1.09$ & $p^{*}=0.39$ \\
\hline $\begin{array}{l}\text { Beta-2 } \\
\text { microglobulin }\end{array}$ & $31.74 \pm 5.37$ & $27 \pm 6.16$ & $p^{*}=0.046^{*}$ \\
\hline
\end{tabular}

\begin{tabular}{|c|c|c|c|}
\hline & Cases & Controls & \\
\hline \multicolumn{4}{|l|}{ Comorbidities } \\
\hline Diabetes & Cases & Controls & \\
\hline Yes & $4(12.9 \%)$ & $9(29 \%)$ & \multirow{2}{*}{$p^{*}=0.88$} \\
\hline No & $6(19.4 \%)$ & $12(38.7 \%)$ & \\
\hline HBP\| & Case & Controls & \multirow{3}{*}{$p^{*}=0.012$} \\
\hline Yes & $5(16.1 \%)$ & $19(61.3 \%)$ & \\
\hline No & $5(16.1 \%)$ & $2(6.5 \%)$ & \\
\hline Heart Disease & Cases & Controls & \multirow{3}{*}{$p^{*}=0.097$} \\
\hline Yes & $7(22.6 \%)$ & $8(25.8 \%)$ & \\
\hline No & $3(9.7 \%)$ & $13(41.9 \%)$ & \\
\hline
\end{tabular}

${ }^{*} \mathrm{p}=$ Level of significance; ${ }^{\dagger} \mathrm{BMI}=$ Body mass index $\left(\mathrm{kg} / \mathrm{m}^{2}=\right.$ Kilogram $/$ square meter $) ;{ }^{*} \mathrm{mEq} / \mathrm{L}=$ Miliequivalent/liter; ${ }^{5} \mathrm{mg} / \mathrm{dL}=$ Miligram/deciliter; "HBP $=$ High blood pressure

Although there was no difference in the distribution of the polymedication variable between cases and controls, we analyzed possible differences in the main groups of drugs in terms of falls. The contingency tables for each group and their significance are presented in Table 2. Participants in the case group were 10 times more likely to use antihypertensive drugs than those in the control group $(\mathrm{OR}=10,95 \% \mathrm{CI}=1.63-61.46)$. Likewise, the cases were 9 times more likely to use $B 2$ antagonists than the controls $(\mathrm{OR}=9,95 \% \mathrm{CI}=1.55$ 52.27). Distribution in diuretic therapy showed significant differences, although it was not possible to calculate the odds ratio because there were no patients in the case group treated with diuretics.

Table 2 - Frequency of polymedication and treatment with fall-risk increasing drugs among cases (falls) and controls (no falls) in patients $(n=31)$ receiving hemodialysis at the Nephrology Service of the Infanta Leonor University Hospital. Madrid, Spain, 2019

\begin{tabular}{|c|c|c|c|}
\hline Oral Antidiabetics & Cases & Controls & \\
\hline Yes & $2(6.5 \%)$ & $5(16.1 \%)$ & \multirow{2}{*}{$p^{*}=0.81$} \\
\hline No & $8(25.8 \%)$ & $16(51.6 \%)$ & \\
\hline Antihypertensives & Case & Controls & \multirow{3}{*}{$p=0.007$} \\
\hline Yes & $8(25.8 \%)$ & $6(19.4 \%)$ & \\
\hline No & $2(6.5 \%)$ & $15(48.4 \%)$ & \\
\hline Benzodiazepines & Case & Controls & \multirow{3}{*}{$p^{*}=0.88$} \\
\hline Yes & $4(12.9 \%)$ & $9(29 \%)$ & \\
\hline No & $6(19.4 \%)$ & $12(38.7 \%)$ & \\
\hline Antidepressants & Case & Controls & \multirow{3}{*}{$p^{*}=0.74$} \\
\hline Yes & $1(3.2 \%)$ & $3(9.7 \%)$ & \\
\hline No & $9(29 \%)$ & $18(58.1 \%)$ & \\
\hline Sedatives & Case & Controls & \multirow{3}{*}{$p^{*}=0.95$} \\
\hline Yes & $2(6.5 \%)$ & $4(12.9 \%)$ & \\
\hline No & $8(25.8 \%)$ & $17(54.8 \%)$ & \\
\hline Antihistamines & Case & Controls & \multirow{3}{*}{$p^{*}=0.81$} \\
\hline Yes & $2(6.5 \%)$ & $5(16.1 \%)$ & \\
\hline No & $8(25.8 \%)$ & $16(51.6 \%)$ & \\
\hline
\end{tabular}




\begin{tabular}{lccc}
\hline Oral Antidiabetics & Cases & Controls & \\
\hline B2 Antagonists & Case & Controls & \\
Yes & $6(19.4 \%)$ & $3(9.7 \%)$ & $\mathbf{p}=\mathbf{0 . 0 0 9}$ \\
No & $4(12.9 \%)$ & $18(58.1 \%)$ & \\
\hline Polymedication & Case & Controls & $\mathrm{p}^{*}=0.363$ \\
Yes & $1(3.2 \%)$ & $5(16.1 \%)$ & \\
No & $9(29 \%)$ & $16(51.6 \%)$ & \\
\hline
\end{tabular}

${ }^{*} p=$ Level of significance

We analyzed the distribution of HD variables as recorded by the dialysis machine, in addition to the hemodynamic values of blood pressure, heart rate and weight recorded by the nursing team before and after dialysis. Table 3 presents the results.

Table 3 - Differences in dialysis and hemodynamic session variables between cases (falls) and controls (no falls) in hemodialysis patients $(n=31)$ at the Nephrology Service of the Infanta Leonor University Hospital. Madrid, Spain, 2019

\begin{tabular}{|c|c|c|c|}
\hline $\begin{array}{l}\text { Hemodialysis }(H D) \text { session } \\
\text { variables }\end{array}$ & Cases & Controls & \\
\hline $\mathrm{UF}^{*}$ & $2801.9 \pm 764.28$ & $2384.37 \pm 976.17$ & $\mathrm{p}^{\dagger}=0.251$ \\
\hline $\mathrm{Kt}^{\ddagger}$ & $57.16 \pm 4.94$ & $58.4 \pm 5.45$ & $\mathrm{p}^{\dagger}=0.567$ \\
\hline $\mathrm{Kt} / \mathrm{v}^{\S}$ & $1.79 \pm 0.3$ & $1.92 \pm 0.42$ & $\mathrm{p}^{\dagger}=0.375$ \\
\hline \multicolumn{4}{|l|}{ Hemodynamic variables } \\
\hline SBP\| preHD" $(\mathrm{mmHg})$ & $135.25 \pm 20.17$ & $139.65 \pm 27.2$ & $\mathrm{p}^{\dagger}=0.88$ \\
\hline $\mathrm{DBP}^{* *}$ preHD $(\mathrm{mmHg})$ & $70.66 \pm 14.26$ & $70.35 \pm 10.97$ & $\mathrm{p}^{\dagger}=0.95$ \\
\hline SBP\| postHD"+ $(\mathrm{mmHg})$ & $129.22 \pm 27.67$ & $138.95 \pm 21.61$ & $\mathrm{p}^{\dagger}=0.31$ \\
\hline $\mathrm{DBP}^{* *}$ postHD ${ }^{+\dagger}(\mathrm{mmHg})$ & $69.22 \pm 13.53$ & $73.1 \pm 12.16$ & $\mathrm{p}^{\dagger}=0.45$ \\
\hline 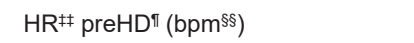 & $71.6 \pm 9.86$ & $79.09 \pm 13.45$ & $\mathrm{p}^{\dagger}=0.13$ \\
\hline $\mathrm{HR}^{\ddagger \ddagger}$ postHD $\mathrm{D}^{+\dagger}\left(\mathrm{bpm}^{\S \S}\right)$ & $72.1 \pm 8.67$ & $81.24 \pm 12.27$ & $\mathrm{p}^{\dagger}=0.044^{*}$ \\
\hline PreHD weight" $(\mathrm{kg})$ & $79.1 \pm 13.82$ & $71.62 \pm 21.16$ & $\mathrm{p}^{\dagger}=0.32$ \\
\hline PostHD weight ${ }^{\dagger+}(\mathrm{kg})$ & $76.76 \pm 13.54$ & $70.01 \pm 20.69$ & $\mathrm{p}^{\dagger}=0.36$ \\
\hline Intradialysis weight difference $(\mathrm{kg})^{||||}$ & $2.34 \pm 0.88$ & $1.61 \pm 0.89$ & $\mathrm{p}^{\dagger}=\mathbf{0 . 0 4 2}$ \\
\hline
\end{tabular}

${ }^{*} \mathrm{UF}=$ Ultrafiltration; ${ }^{\dagger} \mathrm{p}=$ Level of significance; ${ }^{\ddagger} \mathrm{Kt}=$ Urea clearance multiplied by dialysis time; ${ }^{5} \mathrm{Kt} / \mathrm{v}=\mathrm{Kt}$ divided by the volume of distribution of urea;

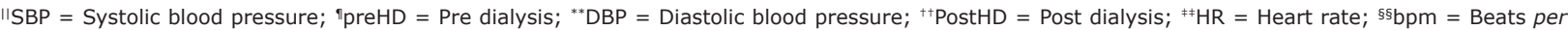
minute; ${ }^{\prime \prime \prime} \mathrm{kg}=$ kilogram

An ROC curve was used to find the discriminatory cut-off point between cases and controls in terms of the variable of intradialytic weight change. The area under the curve was 0.721 , with a CI of $95 \%$ CI (0.526-0.917). The cut-off point was set at $1.1 \mathrm{~kg}, 1.9 \mathrm{~kg}$ and $2.7 \mathrm{~kg}$, which resulted in a sensitivity of $100 \%, 70 \%$ and $40 \%$, respectively and a specificity of $28.6 \%, 66.7 \%$ and $95.2 \%$, respectively. The Youden index $(\mathrm{J}=0.367)$ indicated that the point that determined the highest sensitivity and specificity together was $1.9 \mathrm{~kg}$.
Table 4 presents the means of cases and controls in terms of the variables obtained in the balance test, performed before and after the same dialysis session. This group of variables did not present a normal distribution (K-S $\mathrm{p}<0.05)$, so the Mann-Whitney $U$ test was used to assess whether there were significant differences between cases and controls. 
Table 4 - Differences produced by hemodialysis in the stabilometric variables between cases (falls) and controls (no falls) in patients $(n=31)$ treated with hemodialysis at the Nephrology Service of the Infanta Leonor University Hospital. Madrid, Spain, 2019

\begin{tabular}{|c|c|c|c|c|}
\hline Stabilometry variables & & Case & Controls & \\
\hline \multirow{2}{*}{$\mathrm{X}$ range } & PreHD* & $3.58 \pm 1.62$ & $3.02 \pm 1.12$ & $\mathrm{p}^{\dagger}=0.091$ \\
\hline & PostHD $\ddagger$ & $4.25 \pm 2.27$ & $3.43 \pm 1.74$ & $\mathrm{p}^{\dagger}=0.162$ \\
\hline \multirow{2}{*}{$\mathrm{Y}$ range } & PreHD* & $3.76 \pm 1.54$ & $2.85 \pm 1.21$ & $\mathbf{p}^{\dagger}=0.012^{*}$ \\
\hline & PostHD $\ddagger$ & $4.22 \pm 2.41$ & $3.43 \pm 1.74$ & $\mathrm{p}^{\dagger}=0.113$ \\
\hline \multirow{2}{*}{$V x \max \|$} & PreHD* & $11.83 \pm 6.56$ & $9.76 \pm 4.69$ & $\mathrm{p}^{\dagger}=0.130$ \\
\hline & PostHD $\ddagger$ & $14.53 \pm 9.45$ & $11.26 \pm 5.45$ & $\mathrm{p}^{\dagger}=0.336$ \\
\hline \multirow{2}{*}{ VII y max } & PreHD* & $14.76 \pm 8.81$ & $10.78 \pm 7.93$ & $\mathbf{p}^{\dagger}=0.022^{*}$ \\
\hline & PostHD $\ddagger$ & $17.48 \pm 13.09$ & $12.97 \pm 9.88$ & $\mathrm{p}^{\dagger}=0.101$ \\
\hline \multirow{2}{*}{ Mean V\|I } & PreHD* & $3.87 \pm 2.32$ & $3.13 \pm 1.95$ & $\mathrm{p}^{\dagger}=0.137$ \\
\hline & PostHD $\ddagger$ & $4.25 \pm 2.92$ & $3.39 \pm 1.91$ & $\mathrm{p}^{\dagger}=0.150$ \\
\hline \multirow{2}{*}{ Area 95} & PreHD* & $8.78 \pm 6.96$ & $5.73 \pm 4.25$ & $\mathrm{p}^{\dagger}=0.066$ \\
\hline & PostHD ${ }^{\ddagger}$ & $11.65 \pm 11.04$ & $7.43 \pm 6.07$ & $\mathrm{p}^{\dagger}=0.308$ \\
\hline
\end{tabular}

${ }^{*}$ PreHD = Pre dialysis; ${ }^{\dagger} p=$ Level of significance; ${ }^{\ddagger}$ PostHD = Post dialysis; ${ }^{\S} \mathrm{CI}=$ Confidence interval; || $\mathrm{V}=$ Velocity

The controls presented significant differences $(p<0.05)$ in the PreHD and PostHD data for all the stabilometric variables, except for $\mathrm{V} x$ max. In contrast, the differences related to HD among the cases were not significant $(p>0.05)$ for any of the variables.

\section{Discussion}

This case-control study describes is the first of its kind to describe intradialytic weight change as a factor associated with falls in dialysis patients. The study showed that patients in HD who suffer from falls have greater intradialytic weight changes. When patients arrive at the HD session, they are weighed by the nursing staff, who determine if there is excess weight relative to their reference weight or dry weight. The greater the weight difference, the greater the volume of liquid that should be removed. This usually occurs in patients who do not have good adherence to treatment or dietary guidelines(20). The session lasts an average of 4 hours, so to remove a greater volume, a higher ultrafiltration rate must be used, which can generate a greater risk of intradialytic hypotension(21) and orthostatic hypotension ${ }^{(22)}$. Previous studies have related these events with falls, and this study directly demonstrated that intradialytic weight change is a factor related to the risk of falls. Falls are factors of poor prognosis in patients who receive dialysis ${ }^{(14)}$ and after observing an incidence of falls of $32 \%$, similar to the $37 \%$ described in a recent study(23), it would be interesting to analyze the ability to prevent falls in patients whose intradialytic weight change is greater than $1.9 \mathrm{~kg}$ via prevention protocols.

Based on the other results of this study, patients receiving dialysis who fall also had significantly lower heart rates after HD than the controls. Physiologically, heart rate is supposed to increase when volemia decreases. If this does not occur, brain perfusion may be affected. The decrease in cardiac stimulus may be due to patients' medication and in fact, this study found that patients receiving $\mathrm{HD}$ and who fall are more often treated with beta-blockers, which is consistent with the fact that these drugs are included into the group of those that increase the risk of falls ${ }^{(24)}$. However, the association between postHD heart rate and beta-blocker treatment was not statistically significant, so this hypothesis was ruled out. It seems likely that patients with a limited chronotropic response due to intrinsic or extrinsic causes are at greater risk of falls when undergoing HD.

As for the other drugs analyzed here, all belonging to the group of medications that increase the risk of falls, it was observed that patients who fell took antihypertensives more frequently than those in the control group. These findings are based on the association between lower preHD blood pressure values and increased risk of hypotension(25) and falls ${ }^{(26)}$.

Regarding laboratory values, dialysis patients with a history of falls had higher levels of beta- 2 microglobulin. Increased levels of this protein are due to the passing of time in renal replacement therapy: after 15 years receiving $H D$, about $80 \%$ of patients present with dialysis-related amyloidosis $^{(10)}$, which can affect structures related to 
motor ability such as joints or the central nervous system. In our study, the involvement of these structures was not assessed since they had not been systematically analyzed and were not included in the patients' medical history. The relationship between amyloid deposits and falls has been observed in patients with Parkinson's disease ${ }^{(27)}$. However, to date, a relationship between falls and elevated beta-2 microglobulin or dialysis-associated amyloidosis levels had not been described, at least not in the studies we found. For this reason, we believe that it is necessary to conduct further prospective studies to acquire in-depth knowledge about this relationship.

On comparing the results of the balance tests of the cases and controls, patients who had suffered falls presented greater preHD instability than controls. This preHD alteration was observed in the anteroposterior direction and presented significantly higher values in terms of the range and velocity of movement of the center of pressure (CP). These results are similar to those found by other studies that analyzed patient balance in between dialysis sessions. A recent study found that higher velocity of $\mathrm{CP}$ movement was associated with falls ${ }^{(28)}$; in the present study, patients in the case group also had higher velocity of CP movement, but specifically in anteroposterior displacements. A previous study found a similar result, describing anteroposterior velocity as a fundamental stabilometric variable related to increased risk of falls(29).

After dialysis, both cases and controls experienced an increase in the ranges, speeds and area of displacement of the $\mathrm{CP}$, indicating the acute effect of HD on postural balance. This effect of HD was consistent with the results of other study ${ }^{(9)}$ and it used a similar methodology. Unlike another study ${ }^{(18)}$ which observed an increase in postHD lateral range associated with a higher risk of falls, in our study, we found no significant differences between cases and controls in postHD range and speed of CP movement, although the recorded instability remained higher among patients who had suffered falls. The fact that the increased postHD instability recorded among cases was not statistically significant for any of the stabilometric variables makes us think that the alterations that can result in falls do not improve in the periods between sessions. For this reason, future studies should determine the circumstances of falls, and whether these patients present hemodynamic or biochemical alterations in their daily lives more frequently.

The results shown here can help underpin a review of disconnection and discharge protocols of dialysis sessions, which are the responsibility of a HD unit's nursing staff. This line of research could help test protection and surveillance measures for at-risk patients and verify their effectiveness in order to avoid falls and their consequences.

Limitations of this study include mainly its retrospective methodology. The time between assessments and the fall that defined the cases varied within the 6-month period considered in this study. Furthermore, the fall that defined a case was always outside the hospital and in the period between sessions, but the circumstances and the exact time of the falls were not taken into account.

\section{Conclusion}

This case-control study identified some factors that dialysis unit nurses can pay attention to in order to reduce the postHD incidence of falls. Patients treated with HD who suffer falls are usually hypertensive, take antihypertensives [angiotensin-converting enzyme inhibitor (ACEI) or angiotensin II receptor antagonist (ARA II)] and beta-blockers, have elevated serum beta2 levels microglobulin, and present anteroposterior instability. Unlike the controls, the patients who had a history of falls presented greater intradialytic weight change. Furthermore, the cases also presented lateral instability and a lower heart rate at the end of dialysis than the controls.

\section{References}

1. Hill NR, Fatoba ST, Oke JL, Hirst JA, O'Callaghan CA, Lasserson DS, et al. Global prevalence of chronic kidney disease - A systematic review and meta-analysis. PLoS One [Internet]. 2016 Jul 1 [cited 2021 Jun 28];11(7). Available from: https://pubmed.ncbi.nlm.nih.gov/27383068/

2. Gonzalez-Bedat MC, Rosa-Diez GJ, Fuentes AF, Sola L. International Society of Nephrology Global Kidney Health Atlas: structures, organization, and services for the management of kidney failure in Latin America. Kidney Int Suppl. 2021;11(2):e35-46. doi: https://doi.org/10.1016/j. kisu.2021.01.005

3. Rhee CM, Ayus JC, Kalantar-Zadeh K. Hyponatremia in the Dialysis Population [Internet]. Kidney Int Rep. 2019 [cited 2021 Jun 28];4(6):769-80. Available from: https:// www.ncbi.nlm.nih.gov/pmc/articles/PMC6551474/

4. Kramer H, Yee J, Weiner DE, Bansal V, Choi MJ, Brereton $L$, et al. Ultrafiltration Rate Thresholds in Maintenance Hemodialysis: An NKF-KDOQI Controversies Report. Am J Kidney Dis. 2016 Oct 1;68(4):522-32. doi: http://doi. org/10.1053/j.ajkd.2016.06.010

5. Sars B, Van Der Sande FM, Kooman JP. Intradialytic Hypotension: Mechanisms and Outcome. Blood Purif [Internet]. 2020 Feb 1 [cited 2021 Jun 28];49(1-2):15867. Available from: https://www.ncbi.nlm.nih.gov/pmc/ articles/PMC7114908/ 
6. Juraschek SP, Taylor AA, Wright JT, Evans GW, Miller ER, Plante TB, et al. Orthostatic Hypotension, Cardiovascular Outcomes, and Adverse Events: Results from SPRINT. Hypertension [Internet]. 2020 [cited 2021 Jun 28];75(3):660-7. Available from: https://www.ncbi. nlm.nih.gov/pmc/articles/PMC7261502/

7. Kanbay M, Ertuglu LA, Afsar B, Ozdogan E, Siriopol $D$, Covic $A$, et al. An update review of intradialytic hypotension: Concept, risk factors, clinical implications and management [Internet]. Clin Kidney J. 2020 [cited 2021 Jun 28];13(6):981-93. Available from: https://www. ncbi.nlm.nih.gov/pmc/articles/PMC7769545/

8. Shin S, Chung HR, Fitschen PJ, Kistler BM, Park $\mathrm{HW}$, Wilund KR, et al. Postural control in hemodialysis patients. Gait Posture [Internet]. 2014 Feb [cited 2021 Jun 28];39(2):723-7. Available from: https://www.ncbi. nlm.nih.gov/pmc/articles/PMC3946821/

9. Magnard J, Lardy J, Testa A, Hristea D, Deschamps T. The effect of hemodialysis session on postural strategies in older end-stage renal disease patients. Hemodial Int [Internet]. 2015 Oct 1 [cited 2021 Jun 28];19(4):55361. Available from: https://onlinelibrary.wiley.com/doi/ epdf/10.1111/hdi.12307

10. Tagami A, Tomita M, Adachi S, Tsuda K, Yamada $S$, Chiba K, et al. Epidemiological survey and risk factor analysis of dialysis-related amyloidosis including destructive spondyloarthropathy, dialysis amyloid arthropathy, and carpal tunnel syndrome. J Bone Miner Metab [Internet]. 2020 Jan 1 [cited 2021 Mar 21];38(1):78-85. Available from: https://link.springer. com/article/10.1007\%2Fs00774-019-01028-6

11. Chen X, Qu X. Age-Related Differences in the Relationships Between Lower-Limb Joint Proprioception and Postural Balance. Hum Factors [Internet]. 2019 Aug 1 [cited 2021 Jun 28];14(4):702-11. Available from: https://doi.org/10.1177/0018720818795064

12. Zaninotto P, Huang YT, Di Gessa G, Abell J, Lassale C, Steptoe A. Polypharmacy is a risk factor for hospital admission due to a fall: evidence from the English Longitudinal Study of Ageing. BMC Public Health [Internet]. 2020 Dec 1 [cited 2021 Jun 28];20(1). Available from: https://www.ncbi.nlm.nih.gov/pmc/articles/PMC7690163/ 13. Bowling CB, Bromfield SG, Colantonio LD, Gutiérrez OM, Shimbo D, Reynolds K, et al. Association of reduced eGFR and albuminuria with serious fall injuries among older adults. Clin J Am Soc Nephrol [Internet]. 2016 [cited 2021 Jun 28];11(7):1236-43. Available from: https:// www.ncbi.nlm.nih.gov/pmc/articles/PMC4934847/

14. Song YH, Cai GY, Xiao YF, Chen XM. Risk factors for mortality in elderly haemodialysis patients: A systematic review and meta-analysis. BMC Nephrol [Internet]. 2020 Aug 31 [cited 2021 Apr 4];21(1):377. Available from: https://www.ncbi.nlm.nih.gov/pmc/articles/PMC7457491/
15. López-Soto PJ, De Giorgi A, Senno E, Tiseo R, Ferraresi A, Canella $C$, et al. Renal disease and accidental falls: A review of published evidence [Internet]. BMC Nephrology. 2015 [cited 2021 Jun 30];16(. Available from: https:// www.ncbi.nlm.nih.gov/pmc/articles/PMC4625452/ 16. van Loon IN, Joosten $\mathrm{H}$, Iyasere $\mathrm{O}$, Johansson $\mathrm{L}$, Hamaker ME, Brown EA. The prevalence and impact of falls in elderly dialysis patients: Frail elderly Patient Outcomes on Dialysis (FEPOD) study. Arch Gerontol Geriatr [Internet]. 2019 Jul 1 [cited 2021 Jun 30];83:285-91. Available from: https://www.sciencedirect.com/science/ article/abs/pii/S0167494319301244?via\%3Dihub

17. Golriz S, Hebert JJ, Foreman KBB, Walker BF. The validity of a portable clinical force plate in assessment of static postural control: concurrent validity study. Chiropr Man Ther. 2012;20(1):15. doi: http://doi. org/10.1186/2045-709X-20-15

18. Zanotto T, Mercer TH, Linden ML va. der, Traynor JP, Doyle A, Chalmers K, et al. Association of postural balance and falls in adult patients receiving haemodialysis: A prospective cohort study. Gait Posture [Internet]. 2020 Oct 1 [cited 2021 Jun 30];82:110-7. Available from: https://pubmed.ncbi.nlm.nih.gov/32911095/

19. Martínez-Camblor P, Pardo-Fernández JC. The Youden Index in the Generalized Receiver Operating Characteristic Curve Context. Int J Biostat. 2019 Apr;15(1). doi: http:// doi.org/10.1515/ijb-2018-0060

20. Ipema KJR, Kuipers J, Westerhuis R, Gaillard CAJM, Van Der Schans CP, Krijnen WP, et al. Causes and Consequences of Interdialytic weight gain. Kidney Blood Press Res [Internet]. 2016 Oct 1 [cited 2021 Jun 28];41(5):710-20. Available from: https://www.karger. com/Article/Pdf/450560

21. Thongdee C, Phinyo P, Patumanond J, Satirapoj B, Spilles N, Laonapaporn B, et al. Ultrafiltration rates and intradialytic hypotension: A case-control sampling of pooled haemodialysis data. J Ren Care [Internet]. 2021 Mar 1 [cited 2021 Jun 28];47(1):34-42. Available from: https://onlinelibrary.wiley.com/doi/epdf/10.1111/ jorc. 12340

22. Keane DF, Raimann JG, Zhang H, Willetts J, Thijssen $S$, Kotanko P. The time of onset of intradialytic hypotension during a hemodialysis session associates with clinical parameters and mortality. Kidney Int [Internet]. 2021 Jun 1 [cited 2021 Jun 28];99(6):1408-17. Available from: https://www.ncbi.nlm.nih.gov/pmc/articles/PMC8165353/ 23. Carvalho TC, Dini AP. Risk of falls in people with chronic kidney disease and related factors. Rev. LatinoAm. Enfermagem [Internet]. 2020 [cited 2021 Jun 30];28:1-8. Available from: https://www.ncbi.nlm.nih. gov/pmc/articles/PMC7282714/

24. Lee J, Negm A, Peters R, Wong EKC, Holbrook A. Deprescribing fall-risk increasing drugs (FRIDs) for the 
prevention of falls and fall-related complications: a systematic review and meta-analysis [Internet]. BM] Open. 2021 [cited 2021 Jun 28];11(2):e035978. Available from: https://www.ncbi.nlm.nih.gov/pmc/articles/ PMC7878138/

25. Sands JJ, Usvyat LA, Sullivan T, Segal JH, Zabetakis $P$, Kotanko $P$, et al. Intradialytic hypotension: Frequency, sources of variation and correlation with clinical outcome. Hemodial Int. 2014 Apr;18(2):415-22. doi: http://doi. org/10.1111/hdi.12138

26. Cook WL, Tomlinson G, Donaldson M, Markowitz SN, Naglie G, Sobolev B, et al. Falls and fall-related injuries in older dialysis patients. Clin J Am Soc Nephrol [Internet]. 2006 [cited 2021 Jun 28];1(6):1197-204. Available from: https://cjasn.asnjournals.org/content/1/6/1197.long 27. Keleman A, Wisch JK, Bollinger RM, Grant EA, Benzinger TL, Morris JC, et al. Falls Associate with Neurodegenerative Changes in ATN Framework of Alzheimer's Disease. J Alzheimer's Dis [Internet]. 2020 [cited 2021 Jun 30];77(2):745-52. Available from: https://www.ncbi.nlm.nih.gov/pmc/articles/PMC7580016/ 28. Zanotto T, Gobbo S, Bullo V, Vendramin B, Roma E, Duregon $F$, et al. Postural balance, muscle strength, and history of falls in end-stage renal disease patients living with a kidney transplant: A cross-sectional study. Gait Posture [Internet]. 2020 Feb 1 [cited 2021 Jun 30];76:35863. Available from: https://www.sciencedirect.com/ science/article/abs/pii/S0966636219318016?via\%3Dihub 29. Magnard J, Hristea D, Lefrancois G, Testa A, Paris A, Deschamps T. Implicit postural control strategies in older hemodialysis patients: An objective hallmark feature for clinical balance assessment. Gait Posture [Internet]. 2014 [cited 2021 Jun 30];40(4):723-6. Available from: https://www.sciencedirect.com/science/article/abs/pii/ S0966636214006456?via\%3Dihub

\section{Authors' contribution:}

Study concept and design: Ignacio Perez-Gurbindo, Ana María Álvarez-Méndez, María Teresa Angulo Carrere. Obtaining data: Ignacio Perez-Gurbindo, Rafael PérezGarcía, Patricia Arribas Cobo. Data analysis and interpretation: Ignacio Perez-Gurbindo, Ana María Álvarez-Méndez, Rafael Pérez-García, Patricia Arribas Cobo, María Teresa Angulo Carrere. Statistical analysis: Ignacio Perez-Gurbindo, Ana María Álvarez-Méndez, Rafael Pérez-García, María Teresa Angulo Carrere. Drafting the manuscript: Ignacio Perez-Gurbindo, Ana María ÁlvarezMéndez, Patricia Arribas Cobo, María Teresa Angulo Carrere. Critical review of the manuscript as to its relevant intellectual content: Ignacio Perez-Gurbindo, Ana María Álvarez-Méndez, Rafael Pérez-García, Patricia Arribas Cobo, María Teresa Angulo Carrere.

All authors approved the final version of the text.

Conflict of interest: the authors have declared that there is no conflict of interest. Creative Commons (CC BY).

This license lets others distribute, remix, tweak, and build upon your work, even commercially, as long as they credit you for the original creation. This is the most accommodating of licenses offered. Recommended for maximum dissemination and use of licensed materials. 